\title{
A model of negotiation scenarios based on time, relevance and control used to define advantageous positions in a negotiation
}

\section{Omar Guillermo Rojas Altamirano*}

\begin{abstract}
Models that apply to negotiation are based on different perspectives that range from the relationshipbetweentheactors, game theory or the steps in a procedure. This research proposes a model of negotiation scenarios that considers three factors (time, relevance and control), which are displayed as the most important in a negotiation. These factors interact with each other and create different scenarios for each of the actors involved in a negotiation. The proposed model not only facilitates the creation of anegotiation strategy but also an ideal choice of effective tactics.
\end{abstract}

\begin{abstract}
Resumen
Los modelos que se aplican a la negociación se basan en diferentes perspectivas, que van desde la relación entre los actores, la teoría de juegos o los pasos de un procedimiento. En estainvestigación se propone un modelo de escenarios de negociación que considera tres factores (tiempo, pertinencia y control), que se muestran comolos más importantes en una negociación. Estos factores interactúan entre sí y crean diferentes escenarios para cada uno de los actores involucrados en una negociación. El modelo propuesto no sólo facilita la creación de una estrategia de negociación, sino también una opciónideal detácticas efectivas.
\end{abstract}

Keywords: negotiation, strategy.

Palabras clave: negociación, estrategia.

\section{Introduction}

There are many ways to solve differences between actors; among those we find regulations, courts, markets, and negotiations (Raiffa, 1982; Kersten, Michalowski, Szpakowicz, \& Koperczak, 1991) The negotiation approach to

\footnotetext{
Universidad Panamericana, Campus Guadalajara Correo electrónico: orojas@up edu mx
} 
the resolution of differences should not be perceived as something wrong, according to Rao (1992), since it is a common occurrence in life Negotiation involves making several different decisions (Raiffa, Richardson, \& Metcalfe, 2002) and therefore it is a complex process Furthermore, this complexity is not only due to the number of variables and the interaction between them, but also to other features, such as unpredictability and interaction between the actors (Wheeler \& Morris, 2002)

Most negotiation models focus on the actors involved in the decision making process and not on the possible scenarios under which decisions are made Golden (2008) proposes a Counsel Model, that suggests hiring a person to help and work collaboratively with the counterpart; such a model is based on case studies presented in the trucking industry of the United States when an accident happens Grump (2007) proposes the Temporal Model of Negotiation Linkage Dynamics based on case studies of bilateral negotiations among three governments (United States, Singapore and Australia between 2000 and 2004), this model focuses on the interdependence of the different relationships generated during, before and after the negotiation Finally, another model based on the relationship of the parties involved in the negotiation process is the one studied by Fells (2013), who develops a model made by Halpert (2010) known as Negotiation Success. An Application of the Halpert et al. PathModel, its main contribution being cooperation between the involved parties

Negotiation might also be approached from the point of view of game theory, which studies the strategies followed by the actors, especially in oligopolistic deals In such a competition, players are assumed to be in the same position and therefore they should act according to the decisions taken by their counterpart as a result of the actions carried out regarding the amount of product (Cournot, 1838), price (Edgeworth, 1925), or differentiation (Chamberlin, 1937), to name a few of the most important Sebenius (1992) mentions that game theory is useful in repetitive negotiations where situations and variables are clear and structured, when both players act rationally and therefore the results of the interactions can be predicted However, in reality and most of the cases, negotiation agents do not decide rationally but they rather do it based on emotions or interests (Fisher \& Ury, 1981; Lax and Sebenius, 1986; Bazerman and Neale, 1992) 
Besides game theory, there are other studies that propose models of resolution of negotiations, whose application is broader from the perspective that they use a higher number of variables and assume the complexity of the different deals, see, e g Fisher and Ury (1981), Raiffa (1982), and Lax Sebenius (1986), Kersten (1991), and Bazerman and Neale (1992), among others Most of the models studied in the literature are based on a series of steps that, in the end, are represented in a procedure such as the one from Adair and Brett (2005). In such a study, they propose a model where the first step is the one they call relational positioning, which refers to knowing and identifying the position of each of the parties in the negotiation; the second step is to identify the problem; the third one is to generate feasible solutions and finally, to reach an agreement.

In this paper we propose a model that facilitates setting negotiation strategies and tactics, under different scenarios, resulting from the interaction of some important variables In the following section we show the factors that are considered in order to define the propose Model of Negotiation Scenarios (hereafter mns) These variables are time in which the negotiation takes place, control that each of actors shows over the other, and the relevance of what is being negotiated

\section{Factors of the Model of Negotiation Scenarios}

\section{Influence of time}

Time is a key factor in a company; Bhatia (2012) states that the importance of time, risk and financial return determine the value of a firm. Time is also useful in other business tasks Seshadri and Shapira (2001) state: "Time is one of the more salient constraints on managerial behavior" Negotiation is one of many business tasks with time as a constraint Time is a measure factor useful to establish whether the results of a negotiation are positive or negative Lawson (2001) has found that some companies do not measure efficiency in the short term but in the long run For other companies, the perspective of time is contrary to that mentioned by Lawson Sayman and Önçüler (2009) study the term time inconsistency, which means larger and long-term results are preferred to smaller results but in a short time However this statement is 
only maintained for a certain period; as time goes by, the preferences may change to smaller but short-term results; time inconsistency, therefore, can also play a role in the preference of results

Besides the preference between short-term and long-term, there might be other temporal regions, according to Zauberman and Lynch (2006) Thus, in a negotiation, the results may be presented and occur in three different time regions: the present, the near future and the distant future We understand the present as a short-term perspective $(s t)$, the near future as medium-term $(m t)$, and finally the distant future or the long-term $(\boldsymbol{Z t})$ Furthermore, a negotiator may prefer short-term rewards in contrast to his counterpart who can choose long-term. The influence of time is important in order to establish a model of scenarios in the negotiation and we propose to separate it into the three aforementioned perspectives: $s t, m t$ and $\boldsymbol{l t}$

The time variable that gives the greatest advantage when negotiating is the st, and the one that gives the minor advantage is the 1t In the long run there will be a number of negotiations between the parties involved, just imagine that one of the two parties does not need to have a deal in the long term but in the short term For example, provider $A$ wants to sell a product $X$ to customer $B$ If both of them want to have a long-term relationship they will try to cooperate as much as possible and in these circumstances none have a relative advantage to each other; however, if client $A$ for some reason is interested in purchasing product $X$ for only one time, supplier $A$ will cooperate as client A will compete, in this deal the disadvantage is for supplier $A$ and not for the client $B$

\section{Level of control and power}

The negotiator's position depends heavily on the ability to influence his counterpart; usually, this concept is known as power Garcia (2002) states that a negotiation can be won if power is held According to Raiffa (2002) power is a multifaceted concept; it can mean different things, such as control of information, a competitive advantage, or simply a preferred position Usually the weaker parties overestimate the competitive advantage of the powerful parties The concept of power has been studied by several authors from different perspectives as to their typology (French, Jr, \& Raven, 1959), theirin- 
centives, i.e., for greater organizational position or higher salary (Qian, 1994) or by their level of control (Garcia, 2002), where the powerful do not care about what their partners argue because they know they hold the full power of the negotiation Power is the use of resources to assert one's opinion and its use in a negotiation affects the outcome When one of the parties has more bargaining power, he has sufficient capacity to handle his counterpart and thus directly influence the result. When both sides have the same amount of power, the ability to influence is similar, and when one is lesser, he must submit to the more powerful

For the mns proposed, we consider four levels of power or control according to the economic theory of the market between the supplier and the buyer, see, e g Chamberlin (1937), Dixit and Stiglitz (1977), Krugman (1979), Friedman (1985), Fujita (1988) and Krugman and Obstfeld (2006), among others. The first level is having full control (fc) of the situation, such as in a monopoly If the player doesn't have absolute control, it will then be a duopoly, where there is shared control (sc) and no party has absolute power over the other In third place, when the control is shared not only with a counterpart but several others who hold the same percentage or capacity of intervention, we will call this fragmented control (fc), known in economic theory like monopolistic competition, see Krugman y Obstfeld (2006). Finally, if the player doesn't have influence over the counterpart who decides the result of the negotiation, there is a nonexistent control (nc)

The actor of a negotiation that has tc of the deal will have a very advantageous negotiating position with respect to sc, fc or nc A company that is a market monopoly has tc and is in a better bargaining position than one who is in a market where they share clients with another company and therefore is a duopoly Control is lost depending on whether thenegotiator has more or less market share For example, supplier $A$ is the only vendor that makes product $X$ and customer $B$ is one of hundreds of clients who require it for their production process In this negotiation the most advantageous position will be for supplier $A$ because he will have much greater control than client $B$

Both power and time are variables that affect directly a negotiation but have different strategic and tactical implications when the product value (real or perceived) is different for each one of the actors involved 


\section{Relevance of the object under negotiation}

The reward outcome of a negotiation can benefit the two parties as when the parties decide to cooperate, or benefit only one when they decide to compete (see, e g, Lax and Sebenius, 1986) Other authors (Farmer and Pecorino, 2010) suggest such a difference is the result of asymmetric information where the reward is unilateral because it benefits only one of the parties, or bilateral because the benefit is mutual. In a negotiation, each of the parties will assign a value to the object depending on their own interests; this is the relevance of the object under negotiation

We consider two levels of relevance of the object under negotiation: vital and trivial A product that is vital for one of the parties and trivial for the other generates an asymmetry of information (Farmer \& Pecorino, 2010) and therefore the reward sought by each of the parties is different

The variable relevance refers to the significance that each party assigns to the negotiated object, and is also a function of an advantageous or disadvantageous position when for one of the parties the negotiated object is trivial (not important) and if for its counterpart the object is vital (important), it will be in a disadvantageous position For example, a supplier $A$ that has a product $X$ and is the only one that produces it, therefore the importance of selling or not selling it is vital for him; in contrast if the customer $B$ manufactures product $Z$ with different parts and one of them is the product $X$ and also it can be replaced with another type of raw material will acquire the importance of little relevance and thus trivial, the client $B$ in these circumstances will have an advantageous position

Besides time and control, relevance is the last factor of the mns We will describe the model and its application in the next section

\section{Description and application of the Model of Negotiation Scenarios}

The mns defines a clear structure of the interaction of the three variables proposed that facilitates the selection of strategies and tactics to apply in different negotiation scenarios. All negotiations are different and are modified according to the circumstances and actors involved These different circumstances require a different treatment of negotiation strategies; in this way, the 
mns clarifies the scenario of each of the parties and facilitates the definition of the strategy to follow

In a negotiation a player might find himself in one of the three following positions advantageous, equal and disadvantageous An advantageous position would be when the player has tc of the situation because he might set the conditions or if the product is of trivial importance to the player but vital to the counterpart and finally if the prospect of reward is st for the player and 1t for the opponent A position is equal when both the player and the competitor share control, the product is vital or trivial for both, and both seek rewards in the same time perspective The position is of disadvantage when the player has no control and the partner has tc, when the product is vital but only for the player, and finally when the time perspective is $\mathbf{1 t}$ for the player and st for the counterpart Being able to identify different scenarios for the player and its counterpart, the best strategy and tactics for negotiation can be inferred

The best position in a negotiation is of advantageous type, because it is what gives greatest benefit and facilitates obtaining the top results. An equal position type does not give any advantage to any party, and finally the worst position to negotiate is the disadvantageous one because the negotiator in this place is a deal taker and not a deal maker

By considering each of the three factors at their different levels, we can obtain different scenarios For this research we will propose 24 (three levels of time by four levels of control by two levels of relevance) but they may depend on the level of detail that we have of the greater or lesser degree given for each of the factors. The first factor of the model is time and refers to the timing of the deal that wants to be accomplished The second factor refers to the level of control that the negotiator has over the negotiation in connection to the counterpart, and the third one is the importance of the object being negotiated

The main contribution intended by this model is the integration and combination of the three factors previously described The negotiator must identify his position in time and the level of control and the relevance of the negotiated object, not only from his own perspective but also from that of his counterpart This is the starting point to establish the negotiation strategy Below we present two tables where possible examples of applications of the mns 
Table 1

Applied example of the mns

\begin{tabular}{l|c|l|c|l}
\hline Players & Time & Relevance & Control & Possible position \\
\hline A & It & Trivial & tc & Advantageous \\
\hline B & st & Vital & nc & Disadvantageous \\
\hline
\end{tabular}

In Table 1 we show a possible negotiation scenario where actors $A$ and $B$ have different positions on each of the factors of the mns; in time $A$ has a 1t perspective and $B$ a st one, so $B$ has a better time position but lacks the relevance of control Secondly, the product traded is trivial for $A$ so it is not important, but it is vital to $B$ since it is also part of his subsistence Finally, $A$ has tc and $B$ has nc In the real world actor $A$ can be a public firm with 2,000 employees working in the headquarters' offices and is the only huge company in a town of 30,000 people and in that specific moment is searching for a new supplier of stationary products Consider actor $A$ as a retail company thus stationary products are not an important raw material or product for the core of the business; in the other hand, $A$ is looking for a lt relationship because they don't want to change every month from one supplier to another and at the end has tc because he is the only big firm at town; as actor $B$ is an importer that has received one freight container of stationary products but is the only time he will receive such products, therefore his perspective of time is stbecause he would like to sell everything in one sale, the product is vital for him because is small and is the only product he has, and he has nc because there are tons of suppliers for stationary products in the zone In this situation the advantageous position is for actor $A$ and the disadvantageous one for actor $B$

Table 2

Applied example of the mns

\begin{tabular}{l|c|l|c|l}
\hline Players & Time & Relevance & Control & Possible position \\
\hline A & It & Vital & nc & Disadvantageous \\
\hline B & st & Trivial & tc & Advantageous \\
\hline
\end{tabular}


In Table 2, actor $A$ is at a disadvantageous position because mainly he is an entrepreneur that produces coffee mugs and is looking for his first client, being a huge department store For actor $A$, the seller, the perspective is 1 t because he wants the client to request orders for the next years, of course there are hundreds of producers, importers and companies that commercialize coffee mugs so his control is nc, the coffee mug is vital for him because is the only product in his portfolio On the other hand, the buyer, actor $B$ is a department store with nationwide locations. For this firm coffee mugs are a third kind product so that means it is an accessory and it is not an important product for the store, so the object is trivial, the season is summer and is proved that coffee mugs' highest sells are in winter so acquisition for buyers of coffee mugs is trivial, and has tc because is the most important department store so his market share is high and has tons of coffee mugs suppliers Hence actor $B$ is in advantageous position and actor $A$ in a disadvantageous one

What this model says is that by combining these three factors and having the knowledge to be able to segment and use this model well, many ways of negotiating can be defined. The mns model applied from the perspectives involved in the negotiation such as the buyer and the seller counterpart can offer important conclusions, which can serve as a basis for developing a strategy

\section{Conclusions}

The mns presented considers not only the most important factors such as time, relevance and control, but also the interactions that occur between them and the actors in a negotiation Knowledge of the different scenarios facilitates the establishment of a clear strategy for the best deal; when one of the parties does not know where he is situated in the negotiation, he is likely to make strategic and tactical errors For example, if the product is vital, but not for the counterpart and control is nonexistent for the former and absolute for the latter, with a similar time perspective the strategy for the weakest part will be to try to get the best deal his counterpart offers, but it should be clear that hehas littleinfluence. Along-termstrategy wouldinvolvechanging position of control: if a player currently has a non-existent level, over time 
he can build and reinforce his position Another strategy would be to get a substitute product to reduce the level of dependence on the product and so make it less vital On the other hand, in a position of total control, when the product is trivial for the player and vital to his counterpart, and with a perspective of short-term time but long-term for the counterpart, the strategy should be to protect the position

Mns provides not only a clear view of the stage where a negotiator might find himself, but it also gives clarity on the level of each of the factors and what would be required to improve the position This model helps in a clear way to establish both the position of the counterpart and the negotiators' and facilitates the establishment of strategies that are more effective and aimed at the weaknesses of each negotiation

It is considered necessary to carry out deeper studies to empirically test the effectiveness of the model For further work we propose to study in different negotiating situations trying to predict the results based on the model and then affirm or not its applicability after the real negotiation. A full model using utility functions has also been developed and will be presented elsewhere

\section{References}

Adair, WL, \& Brett, J M (2005, Jan-Feb) "The Negotiation Dance: Time, Culture, and Behavioral Sequences in Negotiation", Organization Science, 16(1): 33-51

Bazerman, M H, \& Neale, M A (1992) Negotiating Rationally. New York, ny: Free Press

Bhatia, A (2012) Value Creation - Linking Information Technology and Business Strategy. Texas: Brown Books Publishing

Chamberlin, E H (1937) “Monopolistic or Imperfect Competition?”, The Quarterly Journal of Economics, pp 557-580

Cohen, P, Greenberg, M, Hart, D, \& Howe, A (1989) “Trial by Fire: Understanding the Design Requirements for Agents in Complex Environments", AI Magazine, 10(3):34-48

Cournot, A (1838) Researches into the Mathematical Principles of the Theory of Wealth. (N T Bacon, Trad ) New York: Macmillan

Edgeworth, F Y (1925) "Papers Relating to Political Economy", in Edgeworth, F Y, Papers Relating to Political Economy (pp 111-142) London: Macmillan 
Farmer, A , \& Pecorino, P (2010, October) "Pretrial Bargaining with Asymmetric Information: Unilateral versus Bilateral Payoff Relevance", Southern Economic Journal, 77(2): 369-384

Fells, R (2013) "Negotiation Success-An Application of the Halpert et al Path Model", Negotiation and Conflict Management Research, 6(2): 133-150

Fisher, R, \& Ury, W(1981) Getting to Yes, Negotiation Agreement Without Giving In. New York, ny: Penguin Books

French, J , Jr , \& Raven, B (1959) “The bases of social power”, in Cartwright, D, Studies in social power (pp 150-167) Ann Arbor: University of Michigan Press

Garcia, S M (2002, Sept ) "Power and the Illusion of Transparency in Negotiations", Journal of Business and Psychology, 17(1): 133-144

Golden, J (2008, July) “The Negotiation Counsel Model”, Negotiation Journal, pp 371-378

Grump, L (2007, April) “A Temporal Model of Negotiation Linkage Dynamics”, Negotiation Journal, pp 117-153

Kersten, G, Michalowski, W, Szpakowicz, S, \& Koperczak, Z (1991) "Restructurable Representations of Negotiations", Management Science, 37(10): 1269-1290

Lawson, M B (2001, Aug) "In Praise of Slack: Time is of the Essence", The Academy of Management Executive (1993-2005), 15(3): 125-135

Lax, D A, \& Sebenius, J K (1986) The Manageras Negotiatior. New York: The Free Press

Lynch Jr, JG, \& Zauberman, G(2006, Spring) "When do You Want It? Time, Decisions, and Public Policy", Journal of Public Policy \& Marketing, 25(1): 67-78

Qian, Y (1994, July) "Incentives and Loss of Control in an Optimal Hierarchy", The Review of Economic Studies, 61(3): 527-544

Raiffa, H (1982) The Art and Science of Negotiation. Cambridge, ma: Harvard University Press

Raiffa, H , Richardson, J, \& Metcalfe, D (2002) Negotiation Analysis. Cambridge, ma: The Belknap Press of Harvard University Press

Sayman, S , \& Önçüler, A (2009, Mar ) "An Investigation of Time Inconsistency", Management Science, 55(3): 470-482

Sebenius, J K (1992, Jan) "Negotiation Analysis: A Characterization and Review", Management Science, 38(1): 18-38

Seshadri, S, \& Shapira, Z (2001, May) "Managerial Allocation of Time and Effort: The Effects of Interruptions", Management Science, 47(5): 647-662

Wheeler, M , \& Morris, G (2002, Jun ) "Complexity Theory and Negotiation”, Har$\begin{array}{lllll}\text { vard Business } & \text { School } & \text { Publishing, } & \text { pp } & 1-15\end{array}$ 